\title{
Study on the prevalence of donkey trypanosomosis in Awi zone northwest Ethiopia
}

\author{
Hailegebrael Bedada ${ }^{1}$ and Shimelis Dagnachew ${ }^{2}$ \\ ${ }^{1}$ Samara University, Email: goraw17@gmail.com, \\ ${ }^{2}$ University of Gondar, Email:dagne2121@gmail.com
}

\begin{abstract}
The study on trypanosomosis of donkeys was conducted from October 2009 to March 2010 in four districts of Awi zone including Jawi district of tsetse infested, Abadera and Chara districts found at the edge of tsetse infested area and Dangla of tsetse free district. A total of 384 randomly selected donkeys (86 from Abadera, 87 from Chara, 94 from Dangla and 117 from Jawi) were sampled and examined using haematocrit centrifugation technique. The overall prevalence of trypanosomosis of donkeys was $1.6 \%(n=6)$. The observed prevalence was not significantly $(\mathrm{P}>0.05)$ different among the four districts. Trypanosoma vivax (75\%) and Trypanosoma congolense (25\%) were the most common trypanosome species encountered during the study period. No significance difference was observed between male and female donkeys both in prevalence of infection and mean PCV $(\mathrm{P}>0.05)$. The mean PCV of infected donkey $(23.50 \pm 3.782)$ was significantly $(\mathrm{P}<0.05)$ lower than that of non infected donkeys $(34.70 \pm 4.44)$. The body condition score of the donkey was significantly associated with both prevalence of infection and mean PCV (P $<0.05)$. The study revealed that trypanosomosis in donkeys in the study areas indicates the presence of both cyclical and non-cyclical transmitted trypanosomes which require inclusion of equines in the control program of trypanosomosis in the study areas.
\end{abstract}

Keywords: Awi, Donkey, Ethiopia, Prevalence ,Trypanosomosis.

http://dx.doi.org/10.4314/evj.v16i2.6

\section{Introduction}

Trypanosomosis cause significant loss in animal production and it greatly affect people and animal settlement in considerable parts of world (Ermias Assefa and Getachew Abebe, 2001). Over 10 million square kilometer areas of Africa greatest agricultural potential are infested by tsetse fly, which is the main vector of disease (Dargant et al., 2001). Trypanosomiasis that occurs across more than a third of Africa is arguably the most significant disease 
(ILRAD, 1994). Trypanosomiasis is probable the most serious veterinary and animals production problem in sub Sahara Africa and prevent, or seriously crucial, the keeping of ruminant and equine (Dhollander et al., 2006 and Auty et al., 2008).

In Ethiopia, trypanosomiasis is one of the most important disease limiting livestock productivity and agricultural development due to its high prevalence in the most arable and fertile land of south west and north west part of the country following the greater river basins of Abay, Omo, Ghibe, and Baro with a high potential for agricultural development. Currently, about 220,000 square kilometer areas of the above mentioned area infested with five species of tsetse flies including G. pallidipes, G. morsitans submorsitans, G. fuscipes, G. tachinoides and G. longipennis. Part of the Amhara region is tsetse infested, G. morsitans sub morsitans and G. tachinoides are reported (Langridge, 1976). Donkeys are considered as beast of burden in many developing countries including Ethiopia that stands the second largest donkey population in the world (Alemayehu Mengistu et al., 2001).

According to the study of Rhamato Abebe and Abebe Wolde (2010) in Assosa and Homasha district in Benishangul Gumuz regional state the prevalence of donkey trypanosomosis was $6.3 \%$. Birhanu Shelima et al. (2006b) stated that the prevalence of donkey trypanosomosis in Welayta zone, southern Ethiopia was $28.5 \%$. In other studies the prevalence of donkey trypanosomosis in the Northern Omo zone, southern Ethiopia was 21\% (Kebede Kanchula and Getachew Abebe, 1997). Therefore the objective of the study was to assess the prevalence of donkey trypanosomiasis in selected areas of Awi zone and to investigate the relationship of trypanosome species with the mean PCV.

\section{Materials and Methods}

\section{Study area}

The study was conducted in Awi zone located in Amhara regional state North-western Ethiopia (figure 1). The study area is densely populated with an estimated human population density of about 100\% persons per square kilometer. More than $88 \%$ of the population lives in rural areas and practice subsistence, rain feed cropping combined with extensive grazing of livestock. Approximately $35 \%$ of the land is cultivated, $12 \%$ is used for grazing, $15 \%$ is forest and bush, $23 \%$ is unproductive land and 15\% is classified as unutilized land (CSA, 2008). In the study area there are big rivers with altitude ranging from 1200-2500 m.a.s.l, different vegetation types including grass woodland, 
riverine forest and marshy grassland. The annual rain fall of the area is ranging from $1500-1800 \mathrm{~mm}$ and annual mean temperature ranges from $17.5^{\circ} \mathrm{C}$ to $25^{\circ} \mathrm{c}$. Sampling was done in three districts of Awi zone (Jawi which is found in the belt of tsetse fly with altitude 1200-1700, while Abadera and Chara which are located at the edge of tsetse belt and Dangla which is tsetse free with an altitude of 1500-1800 m.a.s.l (Thomas Cherenet, 2004).

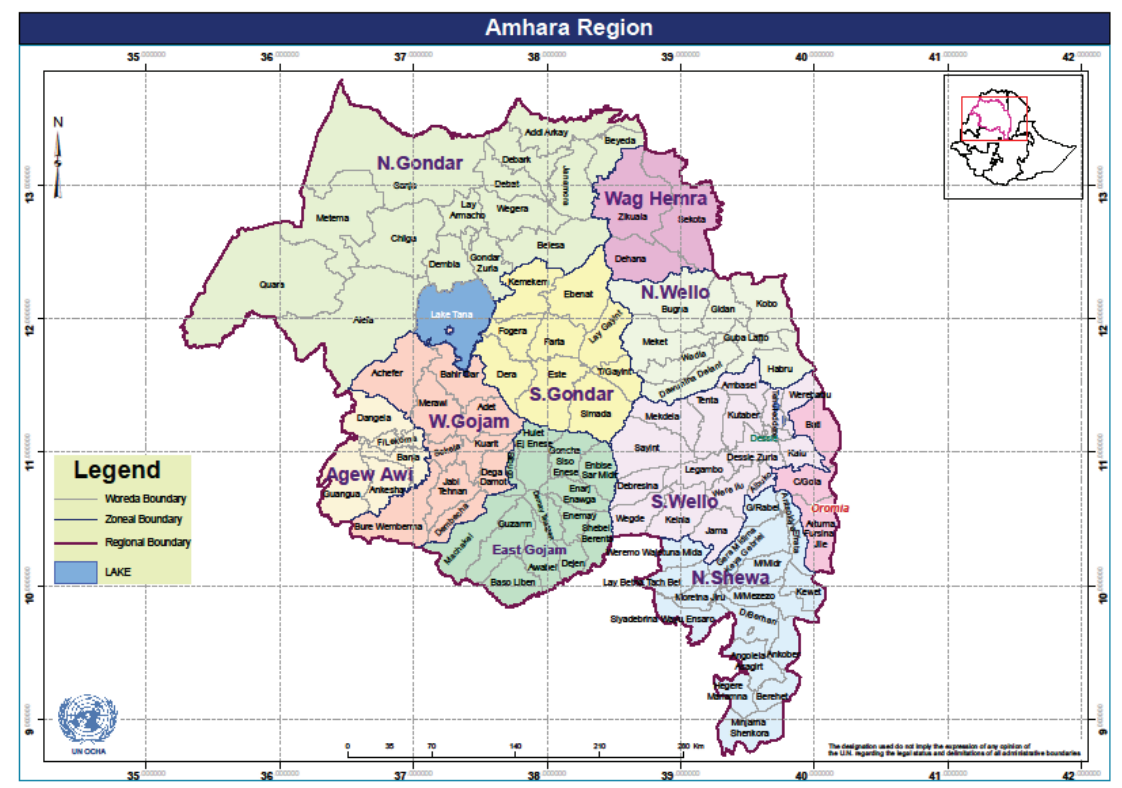

Figure 1: District location of Amhara regional state showing the study area (UN OCHA, 2002).

\section{Study Animal}

The study populations were indigenous breed of donkeys kept under extensive husbandry which allows free grazing, usually mixed with other livestock in the village. Donkeys are the main type of pack animals in the area use to transport people, water, house hold materials, crops and fire wood from place to another (BoARD, 2007).

\section{Study Design and Methodology}

The donkey population in the study area is estimated to be 16,489 (CSA, 2008). A total of 384 donkeys were selected from the study population by the simple random sampling technique according to Thrusfield (1995) with $95 \%$ of confidence interval, $5 \%$ of desired absolute precision and $50 \%$ of expected 
prevalence. The age of selected animals was determined by dentition (Crane, 1997) and body condition scoring was based on the criteria of Nicholson and Butterworth (1986) and (NEWC, 2005). About 384 heads of donkeys (86 in Abadera district, 87 in Chara district, 117 in Jawi district and 94 in Dangla district) were sampled from October 2009 to March 2010.

\section{Parasitological and Hematological Examination}

Blood sample were collected directly from the ear vein and jugular vein of the study animals into heparinized capillary tubes and EDTA coated vaccutainer tubes. Blood samples were examined by dark ground buffy coat method to detect the presence and species of trypanosomes as described by Murray et al. (1983). Blood sample were obtained by puncturing of the marginal ear vein with a lancet and collect directly in to a capillary tube, which has been treated with heparin sealed one end with Cristaseal. The capillary tubes were placed in micro haematocrit centrifuge with the sealed and outer most. After screwing the rotary cover and closing the centrifuge lid, the specimens were allowed to centrifuge at $12000 \mathrm{rpm}$ for five minutes. Tubes were then placed in haematocrit and express the reading as percentage of packed red cell to the total volume of whole blood. According to Murray et al. (1983) stated animals with PCV $<32 \%$ were considered to be anemic put reference. Haematocrit tubes were cut by diamond tipped pencil few millimeters below the junction of buffy coat or plasma level, and the erythrocyte, the contents homogenized on to a clean glass slide and coverage with $22 \times 22 \mathrm{~mm}$ cover slip.

Thin blood smear also done; a small drop of blood from a microhaematocrit capillary tube to the slide was applied to clean slide and spread by using another clean slide at an angle of $45^{\circ}$. The smear was dried by waving it in the air and fixed for two minutes in methyl alcohol, flooded by Giemsa stain for 30-60 minutes, washed using distilled water. Allowed it to dry by standing up right on the rack and examined under the microscope (x100) oil immersion objective lens.

\section{Data Management and Analysis}

At the time of sampling the owner's name, animal age, animal sex and body condition score were recorded. Data on individual animal and parasitological examination result was inserted into MS-excel sheets program to later a data base and transferred to SPSS software programs of the computer before analysis (SPSS, 17). Descriptive statistics, confidence interval, student t-test and chi-square analysis was used to express results and compare variables. 
The prevalence rate of trypanosome infection was calculated as the number of parasitological positive animals as examined by the buffy coat method divided by the total animals investigated at that particular time. Confidence intervals (95\%) for the PCV of trypanosome infected and not infected were calculated. Student t-test was utilized to compeer the mean PCV and hemoglobin concentration of the parasitic animals with that of non parasitemic animals.

\section{Results}

\section{Parasitological findings}

A total of 6 donkeys (4 in Jawi, 1 in Abadera and 1 in Chara district) were found to be infected with a prevalence rate of $1.16 \%, 3.42 \%, 1.15 \%$ and $0 \%$ in Abadera, Jawi, Chara, and Dangla districts respectively. The majority of trypanosome infections in the study area were infection due to Trypanosome vivax (table 1). In Abadera and Chara T. vivax was the main trypanosome species, while in Jawi both $T$. congolense and $T$. vivax are important species.

Table 1: The prevalence of donkey trypanosomosis in study area

\begin{tabular}{lcccc}
\hline Site & No of animals examined & Prevalence (\%) & \multicolumn{2}{c}{ Species of trypanosome } \\
& & & T. vivax & T. congolense \\
\hline Abadera & 86 & $1.2 \%$ & 1 & - \\
Chara & 87 & $1.2 \%$ & 1 & - \\
Jawi & 117 & $1.7 \%$ & 2 & 2 \\
Dangla & 94 & 0 & - & - \\
Total & 384 & $1.6 \%$ & 4 & 2 \\
\hline
\end{tabular}

\section{Hematological findings}

The mean PCV of infected animals was significantly lower $(\mathrm{p}<0.001)$ than the mean PCV of non infected animals (table 2).

Table 2: Mean PCV of infected and non infected animals in the study area

\begin{tabular}{lccc}
\hline Condition & Number & Mean PCV (\%) & SD \\
\hline Infected & 6 & 23.50 & 3.78 \\
Non infected & 378 & 34.70 & 4.44 \\
\hline Total & 384 & 33.98 & 4.14 \\
\hline
\end{tabular}




\section{Trypanosome species and the linkage with PCV and BCS}

Anemic condition was measured by mean PCV during the parasitemic time when infected; both T. vivax and T. congolense infection reduce PCV compared to non infected animals. The mean PCV values of and body condition score of $T$. congolense infected animals was less than the mean PCV values and body condition score of $T$. vivax infected animals but not statistically significant. The mean PCV of infected donkeys $(23.50 \pm 3.782)$ was significantly $(\mathrm{P}<0.05)$ lower than that of non infected donkeys (34.70 \pm 4.259$)$. Using a PCV value of $32-50 \%$ as a normal value $8.4 \%$ of infected and $83.3 \%$ of the non infected animals were found to be anemic. On the other way significance $(\mathrm{P}<0.05)$ variation was observed between animals with good $(35.15 \pm 4.17)$ and poor $(32.84 \pm 4.44)$ body condition score (BCS).

Table 3: The effect of Trypanosomes species on PCV and BCS of infected donkeys

\begin{tabular}{|c|c|c|c|}
\hline Species & Number & $\mathrm{PCV}( \pm \mathrm{SD})$ & $\mathrm{BCS}( \pm \mathrm{SD})$ \\
\hline T. congolense & 2 & $20.67 \pm 1.53$ & $2.19 \pm 0.58$ \\
\hline T. vivax & 4 & $27 \pm 3.46$ & $2.51 \pm 0.41$ \\
\hline Total & 6 & $25.32 \pm 2.74$ & $2.75 \pm 0.4$ \\
\hline
\end{tabular}

\section{Trypanosome infection and the linkage with age and sex}

The prevalence of trypanosome infection between age categories of less than two years old and above two years old was not significant $(\mathrm{P}>0.05)$ even if prevalence is higher in above two years old donkeys. The prevalence of trypanosome infection was higher in female (2.02 \%)than male $(1.075 \%)$ animals but it was not statistically significant $(\mathrm{P}>0.05)$.

\section{Discussion}

The results suggest that trypanosome is an important disease of donkeys in Awi zone. The presence of trypanosome infection in Jawi district (tsetse infested) was higher than the trypanosome in Abadera and Chara districts (tsetse free) that found at the edge of tsetse belt but study in Dangla district reveals that there is no evidence of trypanosome infection. This is might be due to the location of our sampling site.

The overall point prevalence (1.6\%) of trypanosome infection recorded in donkeys in this study is generally low compared to previous reports of $18.2 \%-28.5 \%$ in different district of southern Ethiopia and 6.30\% in Assosa and Homosha districts in Benishangul Gumuz, Northwest Ethiopia (Birhanu Shelima et al., 
2006; Rhamato Abebe and Abebe Wolde, 2010). The prevalence of trypanosome infection in equine is low because they are not often the preferred host for tsetse as a result less exposed to the challenge as compared to cattle that normally graze over long distance (Radostits et al., 2007). As all these studies used the buffy coat method of diagnosis, the observed differences in prevalence between the present and previous studies cannot be methodological but might be due to reduced tsetse challenge as a result of increased agricultural activities and tsetse control interventions carried out by governmental and nongovernmental organizations. Furthermore, investigator competence to detect trypanosomes and variations in geographical and climatic conditions may play a part. The finding that $T$. vivax is the most prevalent trypanosome species in donkey in this study is in agreement with previous reports of Kebede Kanchula and Getachew Abebe (1997) and Wondwessen Yimam (1993). However, it is inconsistent with reports of Rhamato Abebe and Abebe Wolde (2010), Ermias Assefa and Getachew Abebe (2001) and Birhanu Shelima et al. (2006a, b) in which $T$. congolense was reported to be the predominant species.

The diagnostic capability of buffy coat method is among the factors to be considered because the diagnosis of trypanosome by direct parasitological technique is feasible in the acute state of illness, when the blood is colonized by a large number of parasites. In the chronic state of the illness, which is characterized by low parasitemia, a good parasitological diagnosis is rather difficult that the sensitivity of buffy coat method was very low relative to PCR based diagnosis. Thus, more sensitivity technique such as serology, and PCR should use for effective diagnosis (Pinchbeck, et al., 2008). So, lower prevalence in the study area also might be due to the limitations of the buffy coat technique employed.

Trypanosoma congolense in donkey causes chronic infection with longer persistence in blood (Mattioli et al., 1994). The prevalence was significantly higher in Jawi than other districts as it found within tsetse belt while Abadera and Chara found at the edge of tsetse infested area and Dangla is free of tsetse fly. Similar findings has also been reported from a study in Gambia (Snow et al., 1996) where prevalence of trypanosome was higher in horse and donkey in areas with high tsetse challenge compared with sites with relatively few or no flies. Of the four study sites, trypanosome infection was found only in tsetse infested area and areas found at the edge of tsetse infested area. The in ability to detect trypanosome infection in Dangla district is most likely associated with the absence of tsetse flies so that the transmission capability of trypanosomes by other biting flies might be limited in donkeys. This study confirms earlier 
study of Alekaw Sinshaw et al. (2006) in three districts bordering Lake Tana in Amhara Regional state where no trypanosomes detected in equines examined due to absence of tsetse flies in the study areas even though, a large population of other biting flies such as Stomoxys and Tabanus were present.

Being Jawi district is tsetse infested both cyclically transmitted T. congolense as well as non-cyclically transmitted $T$. vivax were encountered. The control of the disease, predominantly by the use of trypanocidal drugs, could result in failure of the drug to eliminate the parasite completely due to the development of resistant strains against the drug. Many studies (Leak et al., 1993; Yilma Jobre and Malone, 1998) have indicated T. vivax is highly susceptible to treatment while the problem of drug resistance is higher in T. congolense. The presence of many drug venders, and drug administration largely by unprofessional in the presence of $T$. congolense in the Jawi district may explain the increase in the prevalence even the control strategies are still taking on.

The study shows that, both the occurrence of trypanosome infection and mean PCV were found to be independent of sex $(\mathrm{P}>0.05)$. This finding is consistent with previous reports from Gambia (Dhollander et al., 2006) and other literature (Secka, 2003). The study show that donkeys in poor body condition had significantly higher prevalence and lower mean PCV than those in good body condition. This condition is in line with what has been stated in other equine trypanosomiasis related studies. Seifert (1996) indicated that trypanosome infection causes a progressive loss of condition, weight loss and animals become easily exhaustive. The detection of anemia or lower PCV in trypanosome infected donkeys in this study is quite in agreement with other several studies (Birhanu Shelima et al., 2006a; Rhamato Abebe and Abebe Wolde, 2010). However, the observation of anemia in $8.4 \%$ of none infected donkeys and the fact other disease of parasitic origin could also produce anemia posed difficult to associate the low PCV observed in this study with trypanosomosis. A higher infection rate observed in adult animals of above two years of age in the study area is definitely in agreement with (Rhamato Abebe and Abebe Wolde, 2010). Even if absence or lower rate of trypanosome in the young is not clearly understood, some literatures (Fimmen et al., 1999) suggest that this could be associated to the fact that animals travel long distance for grazing, draught as well as to transport harvested crop from field to the home 
and from home to market to tsetse challenge areas could result in a relatively higher prevalence of trypanosomosis in adults as compared to younger animals.

\section{Conclusion and recommendation}

This is the first study to address the problem of donkey Trypanosomosis in Awi zone. The study disclosed that $T$. vivax and $T$. congolense are the most important trypanosomes in donkey in the study area. The species of trypanosome and the prevalence was higher in the areas found under tsetse belt (Jawi) than areas found at the edge of tsetse belt as well as the area out of the belt but not significance. This study also indicated that trypanosome infection in donkeys resulted significant effect in the mean PCV values and body condition scores compared to the non-infected donkeys. Therefore the study suggest that further investigation of donkey Trypanosomosis is required in order to conquer the problems related to the disease. In addition to investigation of the disease, identification of vectors and consequent control measures against the parasite and the vector is essential.

\section{References}

Abebe, R. and Wolde, A., 2010. Preliminary survey on equine Trypanosomosis and its vector in Assosa and Homasha districts of Benishangul Gumuz Regional state, northwest Ethiopia. Livestock Research for Rural Development, 22 (1):140-145.

Assefa, E. and Abebe, G., 2001. Drug resistance of trypanosome congolense in naturally infected donkey in north Omo zone, southern Ethiopia. Veterinary parasitology, 99:152-162

Auty, H., Mundy, A., Fyumagwa, R.D., Picozzi, K., Welburn, S. and Hoare, R., 2008. Management of horse under high challenge from trypanosomes: A case study from Serengeti Tanzania. Veterinary Parasitology, 4:154(3-4):233-41.

BoARD, 2007. Annual report. Bureau of Agriculture and Rural Development, Amhara region, Bahir Dar, Ethiopia.

Caren, M., 1997. Medical in the professional hand book of donkey. $3^{\text {rd }}$ ed, Whittet books limited, 18Anley Road, London, W14 OBY, Pp19-36.

Cherenet, T. and Sani, R.A., 2004. Seasonal prevalence of bovine trypanosomiasis in tsetse infested and tsetse free zone in Amhara region, Northwest Ethiopia. Ondestepoort J. Vet.Res.71: 307-321.

Ethiop. Vet. J., 2012, 16 (2), 65-76 
CSA, 2008. Central Statistical Agency, Statistical Abstract. CSA, Addis Ababa, Ethiopia.

Dargantes, A.P., Reid, S.A. and Copeman, D.B., 2001. Prevalence and incidence of Trypanosomosis in horses and donkeys in the Gambia. Veterinary Parasitology, 101(2):101-14.

Dhollander, S., Jallow, A., Mbodge, K., Kora, S., Sanneh, S., Gaye, M., Bos, J., Leak, S., Brekvens, D., and Geerts, S., 2006. Equine Trypanosomosis in the central river division of the Gambia: a study of veterinary gate-clinic consultation records. Preventive veterinary medicine, 37:152-162.

Fimmen, H.O., Mhelitz, D., Horchiner, F., Korb, E., 1999. Colstoral antibodies and Trypanosoma congolense infection in calves. Trypanotolerance research application. GTZ, No, 116. Germany. Pp 173-178.

ILRAD, 1990. The International Laboratory for research on animal disease Report, Nairobi, Kenya.

Kanchula, K. and Abebe, G., 1997. Donkeys trypanosomiasis in Northern Omo zone, South west Ethiopia. Ethiop. Vet. J., 1: 13-18.

Langridge, W.P., 1976. A tsetse and Trypanosomiasis survey of Ethiopia, Ministry of Overseas Department, London. Halted. Journal of Arid Environment, 1: 357-379.

Leak, S.G.A., 1999.Tsetse biology and ecology: their role in epidemiology and control of trypanosomiasis. Wallingford, Oxon, UK: CAIB publishing.

Mattioli, R.C., Zinsstag, J. and Pfister, K., 1994. Frequency of trypanosomiasis and intestinal parasites in draught donkeys in the Gambia in relation to animal husbandry. Tropical Animal Health and Production, 26:102-108.

Mengistu, A., Agajie, T., Eleanor, F.A., David, G, S. and Mesfin, A., 2001. Use and management of donkey in pre-urban areas of Ethiopia. Center for veterinary medicine, drought animal's power technical report. Pp 89-94.

Murray, M., Trail, J.C.M., Turner, D. A., and Wissococq, Y., 1983. Livestock productivity and trypanotolerance. Network Training Manual, ILCA Addis Ababa (Ethiopia) Pp 4-10.

NEWC, 2005. National Equine Welfare Council, Equine Industry Welfare Guidelines Compendium for Horse, Ponies and Donkey, Body condition scoring for horse and donkey, $2^{\text {nd }}$ ed., Pp 28-29. 
Nicholson, M.J. and Butterworth, M.H., 1986. A guide to condition scoring, Addis Ababa, Ethiopia, ILACA, Rangeland programme.

Pinchbeck, G.L., Morrison, L.J., Langford, J., Meehan, L., Jallow, J. and Christley, R.M., 2008. trypanosomiasis in Gambia; prevalence in working horses and donkey detected by whole genome amplification and PCR, and evidence for interaction between trypanosome species. BMC veterinary research 4 (7). http://www. biomedcentral,com

Radostits, O.M. Blood, D.C., Gay, C.C., Hinchicliff, W.K. and Constable, P.D. 2007. Veterinary medicine. A text book the disease of cattle, sheep, pigs, goats and horse. $10^{\text {th }}$ ed Saunders. Edinburgh, London. Pp 1012-1029.

Secka, B., 2003. Husbandry and Health Constraint for Equines, NARI/ITC/DLS Collaborative Equine Research Part-report. Pp17.

Seifert, H., 1996 Tropical animal health. Kluwer academic publishers. Netherland. Pp 160.

Shelima, B., Jober, Y. and Bogale, A., 2006a. Effects of trypanosomiasis and nematodosis on pack cell volume and body condition of donkey in southern Ethiopia. Ethiop. Vet. J. 10 (2): 125-135.

Shelima, B., Jober, Y. and Bogale, A., 2006b. Management, socioeconomic characteristics and health constraint of donkey in Wolayta zone, southern Ethiopia. Ethiop. Vet. J.10(2): 125-135.

Sinshaw, A., Abebe, G., Desquenes, M. and Yoin, W., 2006. Biting flies and Trypanosoma vivax infection in three highland district bordering Lake Tana, Ethiopia. Veterinary Parasitology, 142:35-46.

Snow, W. F., Wacher, T.J. and Rawling, P., 1996. Observations on prevalence of trypanosomiasis in small ruminants, equines, and cattle, in relation to tsetse challenge, in The Gambia. Veterinary Parasitology, 66: 1-11.

Statistical Package for Social Studies (SPSS): SPSS 11.5.0 for windows, Lead Technologies Inc, U.S.A.

Thrusfield, M., 2005. Veterinary epidemiology. $3^{\text {rd }}$ ed. London, Blackwell Science Ltd. Pp 227-247.

UN OCHA, 2002. United Nations Office for the Coordination of Humanitarian Affairs. Activities and Extrabudgetary. Funding Requirements. 
Yilma, J.M. and Malone, J.B. 1998. A geographic information system forecast model for strategic control of trypanosomiasis in Ethiopia. Veterinary Parasitology, 78: 103-127.

Yimam, W., 1993. Preliminary survey in Equine trypanosomiasis and assessment of packed cell volume at different altitude in North Omo administrative region, DVM Thesis, Faculty of Veterinary Medicine, Addis Ababa University, Debre Zeit, Ethiopia. 